\section{FRI0024 EFFECTIVENESS AND TOXICITY PROFILES OF TRADITIONAL DISEASE MODIFYING ANTIRHEUMATIC DRUGS FOR RHEUMATOID ARTHRITIS}

D Aletaha, JS Smolen. Division of Rheumatology, Department of Internal Medicine III, University of Vienna, Vienna General Hospital, Vienna, Austria

\subsection{6/annrheumdis-2001.1153}

\section{Background}

Objectives To determine the state of application and the fate of traditional disease modifying antirheumatic drugs (DMARDs) during the years before the introduction of new DMARDs including biologic agents.

Methods In a historical prospective analysis the fate of DMARD therapies in 593 patients, comprising a total number of 1319 courses of DMARDs over a period of 2378 patient years, were analysed. DMARD dosages, treatment durations, reasons for discontinuation and adverse events reported by either the patients or physicians as well as CRP and ESR were analysed. Drug retention rates were estimated using Kaplan-Meier-analysis.

Results Methotrexate (MTX), chloroquine (CQ), and sulfasalazine (SSZ) emerged as the drugs most commonly applied during the past 15 years, ${ }^{1}$ whereas gold salts and D-penicillamine (DPA) were used less frequently during the past decade. Three of four therapies had to be terminated for either inefficacy $(37 \%)$ or adverse events $(42 \%) .^{2}$ Patients on high dose therapy had significantly longer median retention rates than those on low dose therapy (SSZ: 34 vs. 7 months; MTX: 73 vs. 39 months). Interestingly, rather than inefficacy, toxicity was the main reason for discontinuation of MTX and SSZ at low doses.

The most commonly encountered adverse events leading to discontinuation were nausea, abdominal pain and rashes (the latter mainly with gold salts and DPA). ${ }^{2,3}$ Median retention rates lasted 36 months).

Conclusion MTX, SSZ and antimalarials became the most commonly used traditional DMARDs for RA. High dose therapy can be continued longer than low dose therapy, and DMARD use is rather limited by toxicity than by inefficacy. Once tolerated, DMARDs can be retained for long periods of time.

\section{REFERENCES}

1 Felson DT, Anderson JJ, Meenan RF. Use of short-term efficacy/toxicity tradeoffs to select second-line drugs in rheumatoid arthritis. A metaanalysis of published clinical trials. Arthritis Rheum. 1992;35:1117-25

2 Fries JF, Williams CA, Ramey D, Bloch DA. The relative toxicity of disease-modifying antirheumatic drugs. Arthritis Rheum. 1993:36:297-306

3 Wolfe F. Adverse drug reactions of DMARDs and DC-ARTs in rheumatoid arthritis. Clin Exp Rheumatol. 1997;15(Suppl 17):S75-81

\section{FRI0025 THE RHEUMATOID ARTHRITIS PATIENT IN THE CLINIC: COMPARING 1319 CONSECUTIVE DMARD THERAPIES}

D Aletaha, IS Smolen. Department of Internal Medicine III, Division of Rheumatology, University of Vienna, Vienna General Hospital, Vienna, Austria

\subsection{6/annrheumdis-2001.1154}

\section{Background}

Objectives Rheumatoid arthritis (RA) patients are prone to receive a series of consecutive disease modifying antirheumatic drugs (DMARDs). This study was performed to reveal possible strategies and treatment patterns with traditional DMARDs in the 1980s and 1990s to serve as a basis for improvement of treatment strategies.
Methods 593 RA outpatients (80.4\% women) from two hospitals who received 1319 consecutive courses of DMARDs (2376 patient years of therapy) were followed from their first presentation throughout the whole course of their disease. Data were collected as dosage, duration of therapy, reason for discontinuation and all adverse effects that had emerged during DMARD treatment. Furthermore, efficacy of individual DMARDs (using CRP and ESR as surrogates) and survival (applying KaplanMeier-estimates) of drug therapy were assessed.

Results Chloroquine (CQ), sulfasalazine (SSZ), and gold compounds (OG, PG) were typical first DMARDs, while penicillamine (DPA), methotrexate (MTX), azathioprine (AZP), cyclosporine (CyA), and combinations were usually used later in the disease course. MTX, SSZ and CQ were the most commonly employed DMARDs throughout the years, ${ }^{1}$ however, SSZ and CQ therapies were mostly followed by MTX. Disease characteristics did not differ between patients with longstanding therapy and those with therapies terminated early. For consecutive DMARDs, there was a decreasing tendency of efficacy (reduction of acute phase response) and of treatment duration (Table $1)$.

\begin{tabular}{llll} 
Abstract FRI0025 Table 1 & & \\
\hline & $\begin{array}{l}\text { CRP reduction } \\
\text { (mg/dl) } \\
\text { (Mean } \pm \text { SD) }\end{array}$ & $\begin{array}{l}\text { ESR reduction (mm/1st } \\
\text { hour) } \\
\text { (Mean } \pm \text { SD) }\end{array}$ & $\begin{array}{l}\text { Duration } \\
\text { (months) } \\
\text { (Mean } \pm \text { SD) }\end{array}$ \\
\hline $\begin{array}{l}\text { 1st DMARD } \\
\text { therapies }\end{array}$ & $-1.3 \pm 3.4$ & $-10.5 \pm 27.5$ & $24.5 \pm 27.7$ \\
$\begin{array}{l}\text { 2nd DMARD } \\
\text { therapies }\end{array}$ & $-0.6 \pm 2.8$ & $-5.7 \pm 23.9$ & $20.4 \pm 23.7$ \\
$\begin{array}{l}\text { 3rd DMARD } \\
\text { therapies } \\
\text { 4th DMARD } \\
\text { therapies } \\
>\text { 4th DMARD } \\
\text { therapies }\end{array}$ & $-0.3 \pm 2.5$ & $-4.7 \pm 20.8$ & $19.8 \pm 22.0$ \\
\hline
\end{tabular}

Acute Phase Response and Duration of Consecutive DMARD Therapies.

Conclusion MTX is the most commonly employed DMARD therapy for RA and is increasingly used as first therapy in newly diagnosed RA. Patients with high disease activity are more often subjected to MTX therapy than to other DMARDs, while those with low activity were more likely to receive SSZ or CQ.

There is a loss of efficacy with increasing number of subsequent therapies. Thus, treatment duration decreases with increasing number of consecutive DMARD therapies.

\section{REFERENCE}

1 Felson DT, Anderson JJ, Meenan RF. Use of short-term efficacy/toxicity tradeoffs to select second-line drugs in rheumatoid arthritis. A metaanalysis of published clinical trials. Arthritis Rheum. 1992;35:1117-25

\section{FRI0026 THERAPEUTIC STRATEGY WITH SODIUM AUROTHIO- MALATE AS FIRST CHOICE DMARD IN EARLY RHEUMATOID ARTHRITIS: PRELIMINARY RESULTS}

${ }^{1} \mathrm{R}$ Sanmartí, 'A Gómez, ${ }^{2} \mathrm{~J}$ Gratacós, ${ }^{2} \mathrm{M}$ Larrosa, ${ }^{1} J \mathrm{D}$ Cañete, ${ }^{1} \mathrm{G}$ Salvador, ${ }^{1} \mathrm{~J}$ MuñozGómez. 'Rheumatology, Hospital Clinic, Barcelona; ${ }^{2}$ Rheumatology, Hospital Del Parc Tauli, Sabadell, Spain

10.1136/annrheumdis-2001.1155 
Background The role of gold salts in the present therapy of rheumatoid arthritis (RA) remains controversial.

Objectives To analyse the clinical efficacy (according to ACR response criteria) of a therapeutic protocol, that includes sodium aurothiomalate as first option DMARD in patients with recent onset RA.

Methods All patients with RA (ACR diagnostic criteria) for less than two years disease duration and no previous DMARD therapy, attending our Rheumatology Units during 1998-99, have been included in a therapeutic protocol, in which the first administered DMARD was sodium aurothiomalate at a dose of $50 \mathrm{mg} /$ week. According to the ACR response at 6 months (no improvement, ACR-20 or ACR-50) patients were treated with methotrexate (MTX) alone, aurothiomalate plus MTX or aurothiomalate alone, respectively. Low dose of steroids $(<10 \mathrm{mg} / \mathrm{d}$ of prednisone) were allowed and intraarticular therapy with triamcionolone hexacetonide was performed in large joint with persistent synovitis.

Results Forty seven $(7 \mathrm{M} / 40 \mathrm{~F})$ patients were included (age:54 \pm 16 years; disease duration: $10 \pm 7$ months; $\mathrm{RF}+: 40(85 \%))$. The percentages of ACR responders at 6 and 12 months were as shown at the Table 1 . Twenty-four per cent of patients discontinued gold salts due to adverse events or inefficacy at 12 months. Aurothiomalate was continued in $61 \%$ of patients as monotherapy and in $15 \%$ of patients in combination with MTX.

\begin{tabular}{lllll}
\multicolumn{5}{l}{ Abstract FRI0026 Table 1 } \\
& Remission & ACR-20 & ACR-50 & No improve \\
\hline 6 months & $11 \%$ & $61 \%$ & $50 \%$ & $28 \%$ \\
12 months & $27 \%$ & $52 \%$ & $30 \%$ & $21 \%$ \\
\hline
\end{tabular}

Conclusion Gold salts still have an important role in RA treatment. The use of aurothiomalate should be taken into account in the present therapeutic strategies of patients with early RA.

\section{FRI0027 5-AMINOLEVULINIC ACID INDUCED PROTOPORPHYRIN IX FORMATION IN ARTHRITIC SYNOVIAL TISSUES: AN APPROACH FOR SYNOVIAL PHOTODYNAMIC THERAPY IN ARTHRITIS}

${ }^{1} \mathrm{G}$ Kirdaite, ${ }^{2} \mathrm{~N}$ Lange, ${ }^{1} \mathrm{~N}$ Busso, ${ }^{2} \mathrm{H}$ Van den Bergh, ${ }^{3} \mathrm{P}$ Kucera, ${ }^{1} \mathrm{~A}$ So. ${ }^{1}$ Laboratoire de Rhumatologie, Université de Lausanne; ${ }^{2} D G R ;{ }^{3}$ Institut de Physiologie, Université de Lausanne, Lausanne, Switzerland

\subsection{6/annrheumdis-2001.1156}

\section{Background}

Objectives To determine the optimal conditions for synovial accumulation of protoporphyrin IX (PpIX) and light induced synovial cytotoxicity in arthritis in vitro and in vivo.

Methods In vitro studies: Synovial biopsies from patients with osteoarthritis $(\mathrm{OA}, \mathrm{n}=9)$, rheumatoid arthritis $(\mathrm{RA}, \mathrm{n}=3)$ and synovial tissues from mice with antigen-induced arthritis (AIA, $n$ $=9$ ) were incubated with different concentrations of 5 -aminolevulinic acid hexyl-ester (h-ALA), a protoporphyrin IX (PpIX) precursor. Tissue PpIX content was determined by microspectrofluorometry. Following photoexcitation, the synovial tissues were evaluated by Sytox-Green fluorescence for cell death.

Animal studies: h-ALA was injected intra-articularly into knee joints of mice with AIA $(n=40)$. Following photodynamic therapy (PDT) in vivo, joint inflammation was assessed by technetium scintigraphy and histology.

Results In human biopsies, the highest fluorescence intensity was observed after incubation with $0.5-1 \mathrm{mM}$ h-ALA. Kinetic studies showed that PpIX accumulation in human tissues reached a peak at $3 \mathrm{~h}$ in OA and increased linearly up to $6 \mathrm{~h}$ in RA. Murine tissues showed highest fluorescence intensity at a concentration of $4 \mathrm{mM}$ in vitro and $8 \mathrm{mM}$ in vivo. By fluorescence microscopy, PpIX was localised to the synovial lining layer, endothelial cells and macrophages. Irradiation of pre-incubated tissues in vitro led to significant cell death. PDT in vivo in AIA led to a statistically significant reduction of histological parameters of joint damage in irradiated joints.

Conclusion Our findings suggest that PDT based on PpIX accumulation in the synovial membrane may be a rational basis for photodynamic synovectomy in arthritic diseases.

\section{FRI0028 SUPPRESSION OF EXPERIMENTAL ARTHRITIS BY TREATMENT WITH A NOVEL DMARD, SMP-114}

F Nishikaku, S Tagashira, K Hagi. Research Center, Sumitomo Pharmaceuticals, Osaka, Japan

\subsection{6/annrheumdis-2001.1157}

Background A more promising therapeutic approach to rheumatoid arthritis would be to maintain joint function. Our studies have been performed with the above goal in mind and showed that some azole compounds meet these requirements. SMP-114, a novel isoxazole derivative, was selected from them and characterised as a compound with antiarthritic activity and without any cyclooxgenase inhibitory activity.

Objectives The objective of these studies was to evaluate the effect of SMP-114 on joint oedema, bone resorption and ankylosis in experimental models of rheumatoid arthritis.

Methods Adjuvant arthritis was induced in Lewis rats by a single injection of Mycobacterium butyricum in the plantar surface of right hindpaw on day 0 , and animals were treated therapeutically (days $10-24$ or days $17-21$ ) with SMP-114. Anti-inflammatory activity was determined by measurements of paw swelling. The protective effect on joint integrity was determined by measuring radiographic and histological changes. Collagen-induced arthritis was induced in DBA/1J mice. Animals were immunised intradermally at the base of the tail with type II collagen (day 0 and day 21). SMP-114 was administered orally (days 0-49). Efficacy was assessed clinically, histologically and radiographically. Results Treatment (days 10-24) of adjuvant arthritis with SMP114 significantly reduced paw oedema with a minimum effective dose of $10 \mathrm{mg} / \mathrm{kg}$. This was accompanied by a more extensive reduction in bone and cartilage destruction around the metatarsal-phalangeal joint, as assessed by histologic and radiographic examinations. SMP-114 was also able to significantly ameliorate full-blown adjuvant arthritis. When daily administration of SMp114 began on day 17, well into the chronic destructive phase, the agent produced a dose-response effect on paw oedema, with a minimum effective dose of less than $2.5 \mathrm{mg} / \mathrm{kg}$. The compound (range $2080 \mathrm{mg} / \mathrm{kg}$ ) demonstrated a capacity for ameliorating joint inflammation (paw oedema) and protecting joint structure coincident with a decrease in the number of osteoclasts in articular lesions in mice with collagen-induced arthritis. SMP-114 also showed anti-fibroblastic effect and, as a result, reduced a frequency of development of ankylosis in these models. This profile 